\title{
KEPUASAN KONSUMEN TERHADAP PELAYANAN DAN PERSEBARAN LOKASI KAFE DI KECAMATAN PADANG BARAT KOTA PADANG
}

\author{
Ika Reski Yolanda ${ }^{1}$ Yurni Suasti ${ }^{2}$ Triyatno $^{2}$ \\ Program Studi Geografi \\ Jurusan Geografi \\ Fakultas Ilmu Sosial Universitas Negeri Padang \\ Email: kukunbuye@gmail.com
}

\begin{abstract}
ABSTRAK
Penelitian ini bertujuan untuk 1) memetakan persebaran kafe, 2) mendeskripsikan kepuasan konsumen terhadap pelayanan kafe dan 3) Menentukan faktor utama pemilihan lokasi kafe. Jenis penelitian ini adalah penelitian deskriptif. Populasi penelitian ini adalah pengunjung kafe dan pemilik kafe. Sampel persebaran kafe diambil secara total sampling, sampel kepuasan konsumen diambil secara purposive sampling yaitu di tiga lokasi tertentu yaitu J-six kafe, Taman Palem dan Safari Garden, dan sampel responden pengunjung kafe di lakukan secara accident sampling. Hasil penelitian ini menunjukan: 1) Persebaran kafe di Kecamatan Padang Barat tersebar tidak merata dengan nilai $\mathrm{T}$ 0,93, 2) kepuasan konsumen dari segi pelayanan kafe berada kategori memuaskan sedangkan kepuasan konsumen dari segi harga dan kepuasan konsumen dari segi fasilitas kafe berada pada kategori memuaskan dan 3) Faktor pemilihan lokasi kafe di kecamatan Padang Barat yaitu kafe berada di pusat kota $(33,33 \%)$, area kafe berada di ruangan outdoor dan indoor, lalu lintas menuju kafe lancar, luas lahan parkir kurang dari $10 \mathrm{~m}^{2}$ (66,66\%), kafe berdekatan dengan sarana pusat perbelanjaan, wisata dan hiburan $(33,33 \%)$, jarak lokasi kafe dengan pesaing $50 \mathrm{~m}-200 \mathrm{~m}$ $(66,66 \%)$ dan jarak lokasi kafe dengan sarana umum kurang dari 50 m (33,33\%).
\end{abstract}

Kata Kunci: Analisis Tetangga Terdekat, Kepuasan Konsumen, Faktor Pemilihan Lokasi, Kafe.

\section{Abstract}

The results of this research 1) mapping the distribution of cafes, 2) describing customer satisfaction with cafe services and 3) Determining the main factors for choosing a cafe location. This type of research is descriptive research. The population of this research is café visitors and cafe owners. The sample of café distribution was taken in total sampling, the sample of customer satisfaction was taken by purposive sampling, namely in three specific locations, namely Cafe Six, Palm Park and Safari Garden, and samples of respondents to the cafe visitors were done by accident sampling. The results of this study show: 1) The distribution of cafes in Padang Barat Subdistrict is spread unevenly with a T value of 0.93, 2) Consumer satisfaction in terms of cafe service is satisfactory while consumer satisfaction in terms of price and customer satisfaction in terms of cafe facilities are in the category satisfying and 3) Factors in choosing the location of cafes in Padang Barat sub-district, namely cafes in the city center (33.33\%), cafe areas in outdoor and indoor spaces, traffic to smooth cafes, parking area of less than $10 \mathrm{~m} 2$ (66, 66\%), cafes adjacent to shopping, tourist and entertainment facilities (33.33\%), distance of cafe locations with competitors $50 \mathrm{~m}-200 \mathrm{~m}$ $(66.66 \%)$ and distance of cafe locations with public facilities less than $50 \mathrm{~m}(33,33 \%)$.

Keyword: Nearest Neightbour Analysis, Customer Satisfaction, Location Selection Factor, Cafe.

${ }^{1}$ Artikel ini ditulis dari skripsi penulis dengan judul Kepuasan Konsumen Terhadap Pelayanan dan Persebaran Lokasi Kafe di Kecamatan Padang Barat Kota Padang untuk wisuda periode Maret 2019 dengan Dosen pembimbing ${ }^{2}$ I Dra.Yurni Suasti, M.Si., ${ }^{2}$ II Triyatno, S.Pd., M.Si 


\section{PENDAHULUAN}

Kafe sudah menjadi lifestyle bagi kebanyakan orang di zaman sekarang, tanpa terkecuali bagi penduduk Kota Padang. Hal ini dapat dilihat banyaknya kafe yang bermunculan di kecamatan Koto Tangah, kecamatan Nanggalo, kecamatan Padang Timur, kecamatan Padang Selatan, kecamatan Lubuk Begalung, kecamatan Pauh dan kecamatan Padang Barat. Dari 11 kecamatan di Kota Padang saat ini terdapat 27 lebih kafe di kecamatan Padang Barat, sedangkan kafe di kecamatan lain memiliki kurang dari 20 kafe.

Marsum (2005) kafe adalah tempat untuk makan dan minum sajian cepat saji dan menyuguhkan suasanan santai atau tidak resmi, selain itu juga merupakan suatu tipe dari restoran yang biasanya menyediakan tempat duduk didalam dan diluar restoran. Kebanyakan kafe tidak menyajikan makanan berat namun lebih berfokus pada menu makanan ringan.

Kafe termasuk dalam klasifikasi restoran kecil. Menurut I Gede Agus Mertayasa (2012) kafe adalah suatu tempat atau bangunan komersil yang menyediakan pelayanan makanan dan mimuman kepada konsumennya. Tujuan operasional restoran adalah mencari keuntungan dan memberikan kepuasan kepada konsumennya.

Kafe biasanya menjadi tempat untuk bersantai dan berkumpul. Setiap kafe memiliki desain interior yang menarik dan unik. Sehingga para pelaku usaha berlombalomba menawarkan konsep kafe yang berbeda untuk menarik minat pengunjung. Selain itu kafe menyediakan berbagai fasilitas seperti Wifi, Live Music, game, dan lain-lain.

Kecamatan Padang Barat mayoritas pengunjung kafe adalah kalangan muda terutama mahasiswa yang gemar untuk bersosialisasi sambil menikmati hidangan kecil, atau sambil bersantai mengerjakan tugas di kafe. Karena itulah bisnis kafe di kecamatan Padang Barat memiliki peluang yang cukup menjanjikan. Hal ini berdampak pada persaingan masing-masing kafe untuk dapat menyajikan yang terbaik, baik itu dari makanan maupun suasana kafe.

Kecamatan Padang Barat banyak kafe yang bertema klasik dan modern, dengan kelebihan masing-masing kafe seperti Kubik kafe, Kinol kafe, The Kafe, Excelso, Kios'k, Bath and Row, Taman Palem, J-six Kafe, Safari Garden,dan lain-lain.

Data Dinas Pendapatan Daerah Kota Padang dan BPM2T Kota Padang tahun 2011 sampai 2017 menunjukan bahwa perkembangan kafe mengalami peningkatan setiap tahunnya. Jumlah kafe di kecamatan Padang Barat tahun 2011 berjumlah 2 kafe, tahun 2012 meningkat sebanyak 7,40\% dari jumlah sebelumnya, pada tahun 2013 kafe mengalami peningkatan sebanyak $11,11 \%$. Dilihat pada tahun 2014 dan 2015 kafe mengalami peningkatan sebanyak 18,52\% dari tahun sebelumnya. Peningkatan yang signifikan terjadi pada tahun 2016 dimana kafe bertambah menjadi 6 kafe, sehingga jumlah peningkatannya mencapai $22,22 \%$ dan pada tahun 2017 jumlah kafe di kecamatan Padang Barat bertambah 2 kafe, sehingga jumlah kafe dari tahun 2011 sampai 2017 menjadi 27 kafe.

Kecamatan Padang Barat merupakan kecamatan yang paling banyak kafe. Jarak antara satu kafe dengan kafe lainnya tidak sampai 300 meter, bahkan ada juga kafe yang baru didirikan, yang lokasinya hanya berjarak sekitar 50 meter dengan kafe yang lama.

Ketepatan pemilihan lokasi merupakan salah satu faktor yang dipertimbangkan oleh seorang pengusaha sebelum membuka usahanya. Faktor pemilihan lokasi usaha tidak hanya didasarkan pada faktor kedekatan dengan target pasar dan ketersediaan infrastruktur, faktor-faktor lainnya juga menjadi pertimbangan pemilik usaha kafe yang berada di kecamatan Padang Barat memilih lokasi usahanya. 
Tjiptono (2007) pemilihan lokasi usaha memerlukan pertimbangan yang cermat terhadap beberapa faktor pemilihan lokasi sebagai berikut: akses, veasibilitas, lalu lintas, tempat parkir, ekspansi, lingkungan, persaingan, dan peraturan pemerintah.

Pelayanan menurut (Gronroos, 1990) adalah suatu aktifitas atau serangkaian aktivitas yang bersifat tidak kasat mata (tidak dapat diraba) yang terjadi sebagai akibat adanya interaksi antara konsumen dengan karyawan atau hal-hal lain yang dimaksudkan untuk memecahkan permasalahan konsumen atau pelanggan. Kualitas pelayanan dapat diketahui dengan cara membandingkan persepsi para konsumen atas pelayanan yang diterima dengan pelayanan yang sesungguhnya konsumen harapkan terhadap atribut-atribut pelayanan suatu perusahaan. Kemudian menurut Parasuratman et.al (dalam Tjiptono, 2005) merangkum lima dimensi pokok yang menentukan kualitas pelayanan, meliputi: Tangible (bukti fisik), Reliability (keandalan), Responsivness (daya tanggap), Assurance (jaminan), Emphaty (empati)

Kotler (2002) mengemukakan bahwa kepuasan konsumen adalah perasaan senang atau kecewa seseorang yang muncul setelah membandingkan antara persepsi/kesannya terhadap kinerja/hasil sesuatu produk dan harapan-harapannya.

Tjiptono (1996) menyatakan bahwa kepuasan atau ketidak puasan konsumen adalah respon konsumen terhadap evaluasi ketidaksesuaian/diskonfirmasi yang dirasakan antara harapan sebelumnya (atau norma kinerja lainnya) dan kinerja aktual produk yang dirasakan setelah pemakaiannya. Kepuasan konsumen merupakan evaluasi purnabeli di mana alternatif dipilih sekurang-kurangnya memberikan hasil (outcome) sama atau melampaui harapan konsumen, sedangkan ketidak puasan timbul apabila hasil yang diperoleh tidak memenuhi harapan konsumen.

Bintarto dan Surastopo Hadisumarno (1978) mengemukakan bahwa pola persebaran dapat ditentukan seragam (uniform), acak (random), mengelompok (clustered) dan lain sebagainya dapat diberi ukuran yang bersifat kuantitatif. Dengan cara demikian maka perbandingan anatara pola persebaran dapat dilakukan dengan baik, bukan saja dari segi waktu tetapi juga dapat segi ruang (space). Pendekatan ini disebut analisis tetangga terdekat. Analisis seperti ini memerlukan data tentang jarak antara satu obyek dengan obyek tetangganya yang terdekat.

Tarigan (2006) teori lokasi adalah ilmu yang menyelidiki tata ruang (spatial order) kegiatan ekonomi, atau ilmu yang menyelidiki alokasi geografis dari sumbersumber yang potensial, serta hubungannya dengan atau pengaruhnya terhadap keberadaan berbagai macam usaha/kegiatan lain baik ekonomi maupun sosial.

Pada studi geografi, lokasi merupakan variabel yang dapat mengungkapkan berbagai hal tentang gejala yang kita pelajari. Jadi, lokasi suatu benda atau suatu gejala dalam ruang dapat memberikan kejelasan pada benda atau gejala geografi yang bersangkutan secara jauh lebih lagi (Sumaatmadja, 1988).

Banyak hal yang harus dipertimbangkan dalam memilih lokasi, sebagai salah satu faktor mendasar, yang sangat berpengaruh pada penghasilan dan biaya. Lokasi usaha juga akan berhubungan dengan masalah efisiensi transportasi, sifat bahan baku, atau sifat produknya, dan kemudahan mencapai konsumen. Lokasi juga berpengaruh terhadap kenyamanan pembeli,dan juga kenyamanan pemilik usaha.

Lokasi yang strategis dalam teori wirausaha diartikan sebagai lokasi yang mudah dijangkau, mudah dilihat konsumen, dan banyak dilalui atau dihuni target 
konsumen yang berpotensi membeli produk, atau jasa yang dijual. Lokasi seperti ini cocok untuk usaha perdagangan barang atau jasa yang harus berhubungan langsung dengan pelanggan. Usaha-usaha yang sangat tergantung dengan lokasi strategis minsalnya: apotek, rumah makan, mini market, bengkel, toko pakaian, dan salon kecantikan.

Tidak ada sebuah teori tunggal yang bisa menetapkan di mana lokasi suatu kegiatan pemasaran itu terbaik dipilih. Berbagai faktor yang ikut dipertimbangkan dalam menentukan lokasi, antara lain ketersediaan bahan baku, upah buruh, jaminan keamanan, fasilitas penunjang, daya serap pasar lokal, dan aksesibilitas dari tempat produksi ke wilayah pemasaran yang dituju, stabilitas politik suatu negara dan kebijakan daerah (Tumanggor, 2011). Pada prinsipnya ada beberapa faktor sebagai bahan pertimbangan untuk memilih lokasi yang cocok, yaitu: (a) Bahan Baku, (b) Pasar. (c) Ongkos Transportasi, dan (d) Tenaga Kerja.

\section{METODE PENELITIAN}

Jenis penelitian ini adalah penelitian deskriptif. Populasi penelitian ini adalah pengunjung kafe dan pemilik kafe. Sampel persebaran diambil secara total sampling terhadap 27 kafe yang ada di Kecamatan Padang Barat, sampel kepuasan konsumen diambil secara purposive sampling yaitu di tiga lokasi tertentu. Pemilihan kafe tersebut adalah kafe yang berada di pusat kota padang, yaitu J-six kafe, kafe yang berada di pusat wisata, yaitu Taman Palem dan kafe yang berada di pusat hiburan, yaitu Safari Garden, dan sampel responden pengunjung kafe di lakukan secara accident sampling, masing-masing 20 orang pengunjung kafe. Data yang dikumpulkan dalam penelitian ini adalah: pertama, titik koordinat kafe untuk menentukan persebaran kafe yang diambil menggunakan GPS, persebaran dipetakan menggunakan teknik analisis tetangga terdekat dan ArcGIS 10.1, kedua, kepuasan konsumen terhadap pelayanan, ketiga, faktor pemilihan lokasi menggunakan analisis persentase.

\section{HASIL DAN PEMBAHASAN}

\section{Kepuasan Konsumen dari Segi Pelayanan Kafe}

Kepuasan konsumen dari segi pelayanan kafe menentukan daya tarik konsumen untuk berbelanja. Dari 16 pernyataan kepuasan konsumen dari segi pelayanan kafe, konsumen memberikan tingkat pelayanan kafe, yakni SM (sangat memuaskan), M (memuaskan), STM (sangat tidak memuaskan). Data tabel 1 menunjukkan bahwa kepuasan konsumen dari segi pelayanan kafe sebagai berikut:

Tabel 1. Kepuasan Konsumen dari Segi Pelayanan Kafe

\begin{tabular}{llcccccccc}
\hline \multirow{2}{*}{ No } & \multicolumn{1}{c}{ Pelayanan Kafe } & \multicolumn{1}{c}{ Tingkat Kepuasan } \\
\cline { 3 - 10 } & $\mathbf{F}$ & $\mathbf{\%}$ & $\mathbf{F}$ & $\mathbf{\%}$ & $\mathbf{F}$ & $\mathbf{\%}$ & $\mathbf{F}$ & $\mathbf{\%}$ \\
\hline 1 & $\begin{array}{l}\text { Menyambut tamu dengan } \\
\text { ramah }\end{array}$ & 37 & 61,6 & 22 & 36,6 & 1 & 1,66 & 60 & 100 \\
\hline 2 & $\begin{array}{l}\text { Karyawan seragam dan } \\
\text { rapi }\end{array}$ & 24 & 40 & 34 & 56,6 & 2 & 3,33 & 60 & 100 \\
\hline 3 & $\begin{array}{l}\text { Karyawan tidak } \\
\text { memandang status sosial }\end{array}$ & 25 & 41,6 & 29 & 48,3 & 6 & 10 & 60 & 100 \\
\hline 4 & $\begin{array}{l}\text { Karyawan melayani } \\
\text { konsumen berkunjung }\end{array}$ & 14 & 23,3 & 25 & 41,6 & 21 & 35 & 60 & 100 \\
\hline 5 & $\begin{array}{l}\text { Karyawan memberi daftar } \\
\text { menu }\end{array}$ & 23 & 38,3 & 25 & 41,6 & 12 & 20 & 60 & 100 \\
\hline 6 & Pelayanan yang cepat & 16 & 26,6 & 31 & 51,6 & 13 & 21,6 & 60 & 100 \\
\hline
\end{tabular}




\begin{tabular}{|c|c|c|c|c|c|c|c|c|c|}
\hline 7 & $\begin{array}{l}\text { Konsumen tidak terlalu } \\
\text { lama memesan makanan }\end{array}$ & 14 & 23,3 & 27 & 45 & 19 & 31,6 & 60 & 100 \\
\hline 8 & $\begin{array}{l}\text { Karyawan selalu ada di } \\
\text { butuhkan }\end{array}$ & 16 & 26,6 & 31 & 51,6 & 13 & 21,6 & 60 & 100 \\
\hline 9 & Makanan Hiegienis & 20 & 33,3 & 29 & 48,3 & 11 & 18,3 & 60 & 100 \\
\hline 10 & Menu bervariasi & 21 & 35 & 28 & 46,6 & 11 & 18,3 & 60 & 100 \\
\hline 11 & $\begin{array}{l}\text { Tampilan makanan } \\
\text { menarik }\end{array}$ & 16 & 26,6 & 34 & 56,6 & 10 & 16,6 & 60 & 100 \\
\hline 12 & Porsi makanan sesuai & 21 & 35 & 20 & 33,3 & 19 & 31,6 & 60 & 100 \\
\hline 13 & Rasa makanan enak & 12 & 20 & 36 & 60 & 12 & 20 & 60 & 100 \\
\hline 14 & $\begin{array}{l}\text { Dekorasi kafe yang } \\
\text { menarik }\end{array}$ & 20 & 33,3 & 22 & 36,6 & 18 & 30 & 60 & 100 \\
\hline 15 & Kebersihan ruang makanan & 11 & 18,3 & 29 & 48,3 & 20 & 33,3 & 60 & 100 \\
\hline 16 & Kebersihan toilet & 13 & 21,6 & 32 & 53,3 & 15 & 25 & 60 & 100 \\
\hline
\end{tabular}

Sumber: Data Primer Yang Diolah, Tahun 2018

Pada tabel 1 diatas dapat dilihat kepuasan konsumen dari segi pelayanan kafe memiliki tiga tingkat kepuasan. Tingkat kepuasan dengan nilai tertinggi adalah menyambut tamu denga ramah sebesar 61,6 persen dengan tingkat kepuasan konsumen sangat memuaskan. Sedangkan nilai terendah adalah menyambut tamu dengan ramah sebesar 1,66 persen, dengan tingkat kepuasan konsumen sangat tidak memuaskan.

\section{Kepuasan Konsumen dari Segi Harga}

Harga makanan menentukan daya tarik konsumen untuk berbelanja. Sebagian besar konsumen memilih harga yang terjangkau, porsi makanan banyak, kualitas rasa dan harga makanan lebih murah dari kafe lain.

Tabel 2. Kepuasan Konsumen dari Segi Harga

\begin{tabular}{|c|c|c|c|c|c|c|c|c|c|}
\hline \multirow{3}{*}{ No } & \multirow{3}{*}{ Harga Makanan } & \multicolumn{8}{|c|}{ Tingkat Kepuasan } \\
\hline & & \multicolumn{2}{|c|}{ SM } & \multicolumn{2}{|c|}{ M } & \multicolumn{2}{|c|}{ STM } & \multicolumn{2}{|c|}{ Jumlah } \\
\hline & & $\mathbf{F}$ & $\%$ & $\mathbf{F}$ & $\%$ & $\mathbf{F}$ & $\%$ & $\mathbf{F}$ & $\%$ \\
\hline 1 & Harga makanan terjangkau & 16 & 26,6 & 40 & 66,6 & 4 & 6,66 & 60 & 100 \\
\hline 2 & $\begin{array}{l}\text { Harga sesuai dengan daya } \\
\text { beli konsumen }\end{array}$ & 43 & 71,6 & 16 & 26,6 & 1 & 1,66 & 60 & 100 \\
\hline 3 & Harga sesuai kualitas & 22 & 36,6 & 34 & 56,6 & 4 & 6,66 & 60 & 100 \\
\hline 4 & Harga sesuai porsi & 19 & 31,6 & 33 & 55 & 8 & 13,3 & 60 & 100 \\
\hline 5 & $\begin{array}{l}\text { Harga makanan lebih } \\
\text { murah dibanding kafe lain }\end{array}$ & 6 & 10 & 39 & 65 & 15 & 25 & 60 & 100 \\
\hline 6 & Harga sesuai cita rasa & 7 & 11,6 & 34 & 56,6 & 19 & 31,6 & 60 & 100 \\
\hline
\end{tabular}

Sumber: Data Primer Yang Diolah, Tahun 2018

Pada tabel 2 diatas dapat dilihat kepuasan konsumen dari segi harga memiliki tiga tingkat kepuasan. Tingkat kepuasan dengan nilai tertinggi adalah harga sesuai dengan daya beli konsumen sebesar 71,6 persen dengan tingkat kepuasan konsumen

\section{Kepuasan Konsumen dari Segi Fasilitas Kafe}

Kepuasan konsumen dari segi fasilitas kafe memberikan penilaian yang berbeda. Peneliti membagi ke dalam tujuh pernyataan. sangat memuaskan. Sedangkan nilai terendah adalah harga sesuai dengan daya beli konsumen sebesar 1,66 persen, dengan tingkat kepuasan konsumen sangat tidak memuaskan. 
Tabel 3. Kepuasan Konsumen dari Segi Fasilitas Kafe

\begin{tabular}{|c|c|c|c|c|c|c|c|c|c|}
\hline \multirow{3}{*}{ No } & \multirow{3}{*}{$\begin{array}{c}\text { Kepuasan Konsumen } \\
\text { dari Segi Fasilitas }\end{array}$} & \multicolumn{8}{|c|}{ Tingkat Kepuasan } \\
\hline & & \multicolumn{2}{|c|}{ SM } & \multicolumn{2}{|c|}{$\mathbf{M}$} & \multicolumn{2}{|c|}{ STM } & \multicolumn{2}{|c|}{ Jumlah } \\
\hline & & $\mathbf{F}$ & $\%$ & $\mathbf{F}$ & $\%$ & $\mathbf{F}$ & $\%$ & $\mathbf{F}$ & $\%$ \\
\hline 1 & Wifi & 27 & 45 & 32 & 53,3 & 1 & 1,66 & 60 & 100 \\
\hline 2 & Spot Colokan & 38 & 63,3 & 22 & 36,6 & - & - & 60 & 100 \\
\hline 3 & Tempat berfoto & 24 & 40 & 36 & 60 & - & - & 60 & 100 \\
\hline 4 & Merayakan ulang tahun & 18 & 30 & 38 & 63,3 & 4 & 6,66 & 60 & 100 \\
\hline 5 & Ruangan $A c$ & 7 & 11,6 & 46 & 76,6 & 7 & 11,6 & 60 & 100 \\
\hline 6 & $\begin{array}{l}\text { Kafe berada di ruangan } \\
\text { outdoor }\end{array}$ & 11 & 18,3 & 43 & 71,6 & 6 & 10 & 60 & 100 \\
\hline 7 & $\begin{array}{l}\text { Kafe berada di ruangan } \\
\text { indoor }\end{array}$ & 13 & 21,6 & 42 & 70 & 5 & 8,33 & 60 & 100 \\
\hline
\end{tabular}

Sumber: Data Primer Yang Diolah, Tahun 2018

Pada tabel 3 diatas dapat dilihat kepuasan konsumen dari segi fasilitas kafe memiliki tiga tingkat kepuasan. Tingkat kepuasan dengan nilai tertinggi adalah ruangan $A c$ sebesar 76,6 persen dengan tingkat kepuasan konsumen sangat memuaskan. Sedangkan nilai terendah adalah Wifi sebesar 1,66 persen, dengan tingkat kepuasan konsumen sangat tidak memuaskan.

\section{PENUTUP}

\section{Kesimpulan}

Kepuasan konsumen dari segi pelayanan kafe, rata-rata responden memilih menyambut tamu dengan ramah, sebesar 61,6 persen dengan tingkat kepuasan konsumen sangat memuaskan.

Kepuasan konsumen dari segi harga makanan, rata-rata responden memilih harga makanan sesuai dengan daya beli konsumen sebesar 71,6 persen dengan tingkat kepuasan konsumen sangat memuaskan

Kepuasan konsumen dari segi fasilitas kafe, rata-rata responden memilih ruangan $A c$ sebesar 76,6 persen dengan tingkat kepuasan konsumen sangat memuaskan.

\section{Saran}

Saran dari hasil penelitian yang ditemukan bahwa masih terdapat beberapa konsumen yang memiliki tingkat kepuasan memuaskan dan sangat tidak memuaskan. Oleh karena itu pihak pemilik kafe di kecamatan Padang Barat disarankan untuk meningkatkan kualitas produk yang lebih bervariasi. Selain itu pemilik kafe juga disarankan untuk meningkatkan kualitas layanan dengan cara memberikan pelayanan dengan cepat, ramah dan komunikatif.

\section{DAFTAR PUSTAKA}

Badan Penanaman Modal dan Pelayanan Terpadu Satu Pintu Kota Padang 2017.

Bintarto,R. Dan Surastopo Hadisumarno, 1978. Metode Analisa Geografi. Jakarta: LP3FS.

Dinas Pendapatan Daerah Kota Padang.2017. Daftar Wajib Pajak Kafe 2017.

Gronroos, 1990. Service management and marketing: Manging The Moment Of Truth In Service Competition Massachusetts.Lexington

I Gede Agus, 2012. Food \& Beverage Service Operational. Yogyakarta: $\mathrm{Cv}$ Andi Offset

Kotler P, K, L. Keller. 2002. Manajemen Pemasaran Edisi Dua Belas Jilid I. Jakarta: PT. Indeks.

Marsum. 2005. Restoran dan segala Permasalahannya. Edisi IV. Yogyakarta: Andi.

Sumaatmadja, Nursid. 1988. Studi Geografi Suatu Pendekatan dan Analisa Keruangan. Bandung: Alumni. 
Tarigan. 2006. Perencanaan Pembangunan Wilayah (Edisi Revisi). Jakarta: Bumi Aksara.

Tjiptono. 1996. Manajemen Jasa Edisi I. Yogyakarta: Andi Offset

Tjiptono. 2005. Service, Quality and Satisfaction. Yogyakarta: Andi Offset

Tjiptono. 2007. Manajemen Jasa. Yogyakarta: Andi Offset 